\title{
Early Warning System of Production and Marketing Price of Seasonal Agricultural Products
}

\author{
Fang Huang ${ }^{1, a}$, Xinjiang Xie ${ }^{1, b}$,Cui Wang ${ }^{1, c}$, Pingzeng Liu ${ }^{2, d}$ \\ 1College of Information Science and Engineering, Shandong Agricultural Engineering Institute, \\ Ji'nan, 250100, China \\ 2 College of Information Science and Engineering, Shandong Agricultural University, Taian, 271018, \\ China \\ ahuang1921@163.com, b xjxie163@163.com, cwangcui411@163.com, dlpz8565@126.com
}

Keywords: Seasonal agricultural products. Production and marketing price linkage. Early warning. System design

Abstract. In view of the problem of extraordinary instability of agricultural products' prices, especially regional and seasonal agricultural products, an early warning system of regional seasonal agricultural products based on the linkage of production and marketing price was designed. The system takes ginger in the surrounding area of Ji'nan, Shandong province, China as an example. It mainly includes four functional modules: The data acquisition module collects farmers' basic information, planting area and expected income; The data processing module tests data standardization and validity; The price pre-warning module uses BP artificial neural network model to predict the price which serves as the basis for the producer's final decision; The system maintenance module mainly modifies and imports the latter data. Through this system, producers can obtain timely and accurate production forecast information, so as to organize production activities reasonably.

\section{Introduction}

In 2016, the Central Rural Work Conference proposed that we should further promote the structural reform of the agricultural supply side. The meeting pointed out that, first of all, we should make the agricultural structure good, tuned and optimize to promote the structural reform of the agricultural supply side. Experts said that this includes three aspects of adjustment and optimization: product structure, operating structure and regional structure. In the environment of current market economy, the market price of agricultural products is greatly influenced by the relation between supply and demand. At the same time, the price itself is affected by natural, social and economic conditions, it is also related to opportunistic factors such as malicious price manipulation caused by speculative activities and international market conditions. The abnormal fluctuation of the agricultural products' price will affect the farmers' income, it will also cause some adverse effects on regional agricultural production and development, and make fluctuation in the price level of other sectors and the whole price level of the national economy.

To improve or solve the problem of abnormal prices of agricultural products, especially regional seasonal agricultural products in the market economy environment, we establish the early warning system linked with production, marketing and price for regional and seasonal agricultural products using the internet and a range of development tools. On the basis of this system, we expect to predict the future price of agricultural products, and provide the necessary early warning information for the producers of agricultural products. Mastering the trend of the change of agricultural products' price will help guide the rational cultivation and management of agricultural products, increase producer income effectively and reach the balance of regional supply and demand of agricultural products. It also enables producers of agricultural products to obtain stable economic income while serving and satisfying social needs. 


\section{Theoretical Framework}

\section{Price Linkage Between Production and Market}

The price linkage mechanism refers to the price adjustment system in which the price of the downstream product is influenced by the fluctuation of the upstream product price. The most important feature of this mechanism is that the price of the downstream products is linked to the upstream product price directly. That is, when the upstream product prices rise, the downstream products will rise; when the upstream product price falls, the downstream product prices will fall.

From the perspective of the whole industry chain, there are three main links for agriculture products during the path from farm to table: production, wholesale and retail. In this sense, the price of agricultural products in broad sense includes three kinds: production price, wholesale price and retail price. The production price is the upstream product price, while the wholesale price and the retail price are the downstream product prices. From the government or consumer's point of view, stabilizing prices is mainly refers to stabilize the retail price of agricultural products; from the perspective of increasing the income of farmers, raising prices is mainly to improve the production prices of agricultural products. Whether it is to increase production prices or lower retail prices, we must straighten up the transfer mechanism between agricultural production, wholesale and retail prices and their interaction with each other, from the perspective of the whole industry chain of agricultural products.

In recent years, the research on the relationship between production price and retail price has been increasing in academic circles, the research focuses on: who plays the leading role and drives the other side in the two kind of price. The empirical analysis of the price transmission mechanism in the United States by Cushing et al., shows that the transmission mechanism from producer price to consumer price is more important than the transmission mechanism from consumer price to producer price [2]. Todd comprehensively analyzes the possible causes of the transmission mechanism of producer prices to consumer prices, uses the regression analysis and the vector autoregressive (VAR) model to do empirical analysis of the US data, and draws the conclude that the transmission mechanism from producer price to consumer price is weak[3]. Shiwei Xu, Zhemin Li, et al. selected the production of agricultural products price index (SCJG) and retail price index (SPLS) as sales price signals, analyzed through the impulse response function and variance decomposition analysis, showed that the transmission effect of the agricultural products' market price in the producing areas to the selling area has become more and more obvious over time. The effect of SPLS in selling area to the SCJG in producing area has gradually increased but it is very little [4]. Guiqin Li discussed the process of vegetable price formation in the whole industry chain, found that the rise of production prices will push retail prices rose sharply, while retail prices did not significantly stimulate the production and wholesale prices, and the main factors that affect the vegetable retail price is the cost of production and yield of vegetables [5].

\section{Research on the Agricultural Products' Price Fluctuation}

In theory, the price of any commodity is determined by supply and demand, and agricultural products are no exception, the price elasticity of demand for agricultural products is smaller, while the elasticity of supply price is larger, when agricultural products price increases in the year ,farmers would be promoted to expand production the next year, thus, we fall into the cyclical cycle of "rising prices of agricultural products - expanding production - supply exceeding demand, lowering prices reducing production - demand and price rising again" -this is the "cobweb theory" [6]. Domestic scholars have made much research on the causes of the price fluctuation of agricultural products. The basic cause of the price formation is the market supply and demand mechanism.

In addition, the production and retail are the head and tail of the agricultural products circulation, there must be mutual influence and interaction between them. As the initial price of agricultural products circulation, the production price of agricultural products will fluctuate under the influence of 
the means of production price, transportation and natural climate. As the terminal selling price, the retail price of agricultural products has strong independent volatility under the influence of market demand, currency liquidity, food safety and many other factors, through the "demand forced" to pull production prices, resulting in corresponding fluctuations.

\section{Farmers Behavior Theory Research}

When making production decisions, farmers not only take profit maximization into consideration, but also take their family situations and limits of management abilities into account. At present, Chinese farmers have been under great influences of their planting habits when making production decision. They usually maintain their traditional habits and the consistency with their neighbors. However, along with the deepening marketization, price can also be a prominent influential factor for farmers' production decision-making; contrarily, farmers' response to price information is hysteretic.

Although one farmer's production decisions cannot directly influence the agricultural products market, all the farmers who have nearly the same decisions might cause supply fluctuation and have significant impact on agricultural products' price fluctuation. But the famers' production decision-making is uncertain, farmers' blind expansion and downsizing or retro-regulation behaviors may lead to the change in agricultural products supply, and further influence on price fluctuation. The costs and profits also exert great influences on agricultural products price fluctuation, driving farmers to adjust the supply of agricultural products, thus affecting the price of agricultural products [7].

\section{Data Sources and Directions}

Taking ginger products in Ji'nan as an example, this paper makes an empirical study on the linkage between production price and retail price by using 2010-2016 year's price index. Among the factors that influence the ginger's price change in production and marketing, planting area, mu output, resident population, per capita income, consumer price index and other data are derived from "Statistical bulletin on national economic and social development" published on the website of Ji'nan Statistics Bureau over the years; Ji'nan officials do not have any data on total inputs, outbound quantities and retail prices, therefore, the total investment and the quantity of outbound transportation are obtained by means of social investigation reports. The retail price comes from the data of three important vegetable wholesale markets in Ji'nan, from the Vegetable Network of China.

\section{System Overall Design}

\section{Requirement Analysis}

The main factors affecting prices are analyzed. Food is the first necessity of the people. The demand for seasonal agricultural products by residents is rigid. The demand of regional seasonal agricultural products is mainly determined by the nutrition and health needs of the human population, the substitution of seasonal products is feasible in health science, but it conflicts with people's preferences, therefore, mutual substitution is limited or negligible if the standard of living reached a certain height.

Price is the mapping relation between supply and demand derived from subjective thinking by market trading body after understanding and analyzing the knowledge behind market information and data. The mapping relation changes with time, and the change of mapping relation leads to the change of price. There is statistical relationship when a large number of transactions exist at the same time. Supply has high elasticity to price, while price has low elasticity to supply, but it has hysteresis effect. Demand has high elasticity to price while price has low elasticity to demand, but it depends on the standard of living; Supply and demand seek balance by interacting with prices, but volatility is unavoidable due to hysteresis effect[8].

Under the market economy, the seasonal agricultural products are affected by the regional price, which will inevitably lead to the market behavior of external transportation. Input and output depends mainly on the price difference inside and outside the system, as well as the quality of products, transportation unit price, freshness and other factors. Of course, consideration should also be given to the different rates of substitution for local products resulting from different habitats, the direct performance is the impact of external transportation on production in the price system. 
As can be seen from the above analysis, the main influence on the price fluctuation of ginger lies in the level of production, the quantity supplied by the market, the price level of foreign transportation, the level of residents' income and the level of energy price.

\section{Model}

After a comprehensive analysis of the factors that affect prices, the following eight factors were chosen as the influencing factors: planting area, mu yield, planting total input, outbound volume, resident population, per capita income of town, per capita income of farmers, and consumer price index. The related data of these factors mostly have nonlinear characteristics, BP neural network is used to build the master model for prediction considering the complexity of price formation systems, and non-necessity of long term prediction of seasonal agricultural products. Analyze the production and marketing price linkage, establish the dynamic forecast model of production and marketing price, simulate the changes in production and marketing price of regional seasonal agricultural products[9].

\section{Functional Analysis}

The early warning system of the Regional and seasonal agricultural products' price provide a platform for agricultural producers to understand the market expectations combining with Internet, data mining, data fitting, dynamic simulation forecasting and other technical means. Through this system, producers can obtain timely and precise production forecast information, so as to organize production activities reasonably. This system mainly includes four modules, they are data acquisition, data processing, price warning and system maintenance (as shown in Fig.1), with the help that the Internet has become popular for urban and that the level of knowledge of producers have generally improved, the application may consider the establishment of a comprehensive information prediction platform, guide the active participation of producer dispersedly, and feed back the income reference when predicting yield.

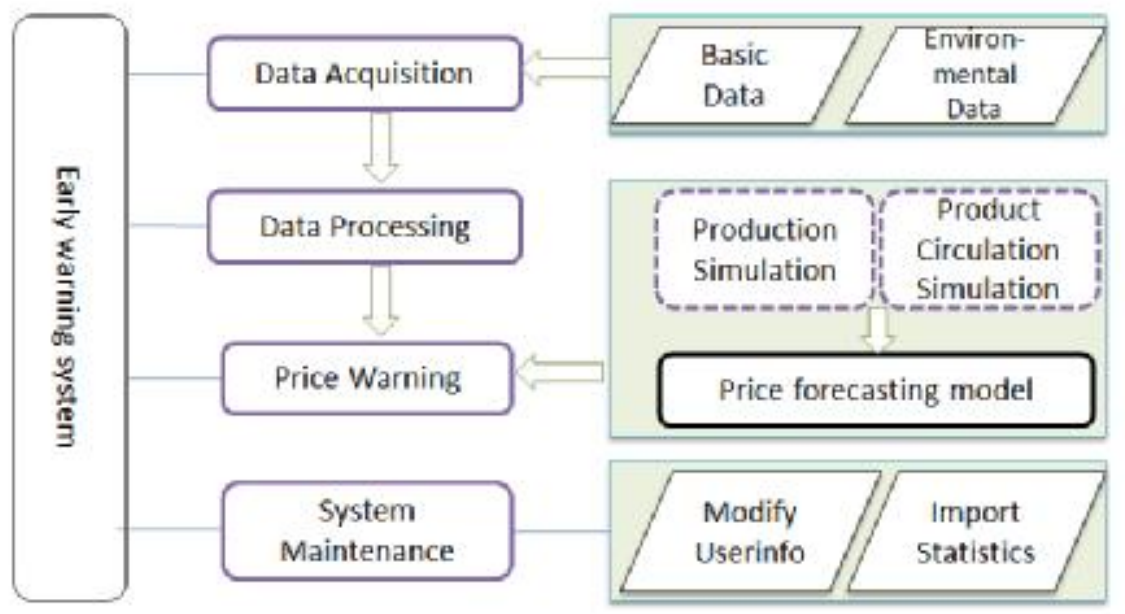

\section{Data Acquisition Module}

Fig. 1 function structure of the system

First, producers need to register in the system, after successful registration, they can log in to the system at any time through their username and password, and they can change the password for their personal login, input basic data such as name, phone, address and so on through user input interface; manually input preplanting area and expected income level. So we can collect the corresponding environmental data of the region's external products by uploading files.

\section{Data Processing Module}

The data processing module examines the standardization and validity of the data submitted by the user, checks the format of the uploaded file, converts it into a standard format and stores it in the database. 


\section{Price Early Warning Module}

Price forecasting and warning function, run in time according to user's request, calculate the forecast price and early warning information feedback to the user, and make it the basis of the decision making and final decision making; users can also view the price charts in previous years, look at the pre-decision data for other producers of the same crop. The module is divided into two parts: production simulation and product flow simulation. The data is extracted from the database and simulated by the production process and the circulation process, and the output data is invoked by the price prediction model integrally.

\section{System Maintenance Module}

This module mainly completes the following functions: modify the user's login password, modify the basic data of the user, adjust the pre planting data, set the format and location of the uploaded file, import the annual economic statistics ,etc.

\section{System Implementation}

\section{Platform Construction}

Established seasonal agricultural products (take ginger in Ji'nan as an example) information platform based on WEB, using B/S architecture. Its core is a WEB server, and set up a database server, each client data request is submitted to the database server by the WEB server and then returned by the WEB server to the requesting client. Through the construction of unblocked information platform, it can transmit the production information in many channels in time, provide basic and accurate forecast and early warning, guide agricultural production, reduce the blindness of agricultural production and the fluctuation of the supply of agricultural products, reduce risks and achieve production expectations[10].

The platform uses the following WEB hardware and software configurations (as shown in Table 1).

Table 1 Hardware and software configuration of platform

\begin{tabular}{|c|c|c|c|c|c|c|c|}
\hline & \multicolumn{4}{|c|}{ Hardware } & \multicolumn{2}{|c|}{ Software } & \multirow{2}{*}{ Network } \\
\hline & Frequency & RAM & HD & Network card & Operating System & Browser & \\
\hline Server & $>=1 \mathrm{Ghz}$ & $>=2 \mathrm{~GB}$ & $>=80 \mathrm{~GB}$ & \multirow{2}{*}{ 100Mbit/s } & $\begin{array}{c}\text { Microsoft } \\
\text { Windows } 7 \\
\text { and above edition }\end{array}$ & \multirow{2}{*}{$\begin{array}{c}\text { IE } 6.0 \text { and } \\
\text { above }\end{array}$} & \multirow{2}{*}{$\begin{array}{c}100 \mathrm{Mbit} / \mathrm{s} \\
\text { Ethernet }\end{array}$} \\
\hline Client & $>=450 \mathrm{Mhz}$ & $>=512 \mathrm{MB}$ & $>=10 \mathrm{~GB}$ & & $\begin{array}{c}\text { Microsoft } \\
\text { Windows XP and } \\
\text { above edition }\end{array}$ & & \\
\hline
\end{tabular}

\section{System Integration and Application}

Install all the application software on the WEB server (Group) instead of the client. This allows real-time flexible applications based on WEB. The application's human-computer interaction logic is separated from the computational logic through custom protocols, when the user accesses the virtualized application on the WEB server, the user computer only needs to transfer the man-machine interaction logic to the server-side through the protocol, server-side set up independent session space for users, the application's computing logic runs in this session space, it transfers the changed human-computer interaction logic to the client, and display it on the client's corresponding device to allow users to feel as if they were running a local application[11].

\section{System Development Strategy}

The system uses Apache as the system's WEB application server software, it has the advantages of cross platform, simple, efficient, stable and safe; uses MySql as a database, it is small, fast, and has low cost of overall ownership and opening sources, so it is a preferred database for small and medium WEB application websites; uses PHP as the script interpreter for the server's front-end, it's syntax has absorbed the characteristics of $\mathrm{C}$ language, Java and Perl, which is conducive to learning and widely used. It is very suitable for developing small and medium-sized WEB applications, and the development speed is relatively fast. Apache+PHP+MySQL combination based on windows is referred to as AMP, it is a golden combination of web development, and all the software is open 
source and free, which can reduce the investment. The versions used in this system are: Apache2.2, PHP5.6 and MySQL5.7.

A dynamic price forecasting model is programmed to be implemented using $\mathrm{R}$ language to predict the price in the system. $R$ is a widely used language in the statistical field, its syntax is very simple and flexible, it supports cross platform applications, and has a set of array and matrix operator, it also has series of coherent and complete data analysis intermediate tools and a powerful graphics function. There is a good interface between R language and other programming languages and databases, PHP also supports the R language program. The R script is called by PHP's function "system", then the results of the R script execution can be got through the file operation of PHP. In this system, the $\mathrm{R}$ language version is R-3.3, the method of running $\mathrm{R}$ program " yuce. $\mathrm{r}$ " in PHP is: "system ("D:IR-3.3lbin\R.exe CMD BATCH --vanilla D:lyuce.r");".

In addition to the platform, development environment and function design, the security of the website can not be ignored. From the point of view of the security of the hardware, we have set up a backup server for the main server, make a reasonable plan for the IP of the internal machine, at the same time, the WEB server is set up as a gateway, using dual network cards. In software, scripts for database operations and user authentication are compiled and executed on the server side, it is not visible to the client, and it has been encrypted and checked many times during delivery. At the same time we install virus protection software, and always pay attention to upgrade, so as to nip in the bud[12].

\section{System Evaluation}

The system is based on the Quantitative Economics Theory, from the point of view of supply and demand balance and price stabilization mechanism, starts with exploring supply mechanism, combined with internet, data mining, data fitting, dynamic simulation prediction and other technical means, pays more attention to the "supply side", while paying close attention to "demand side", so the producers of agricultural products will use this warning system to obtain better production information at the earlier stage of production. And this can help the producers of agricultural products to obtain stable economic income while serving and satisfying social needs, and it is helpful to avoid agricultural injury caused by economic marketization or systematic risk. Compared with the prediction generally adopted in China on the basis of statistical monitoring data, the prediction results of this system have the following characteristics: advance availability, the validity of prediction methods, the innovation of early warning methods and the portability of early warning system applications.

\section{Conclusions}

In the system, the basic tool is internet technology, the central task is price forecasting, the purpose is to make policy early warning. There are many ways to predict, and in general, they infer future data based on past static data and current state data. There is a lot of uncertainty in the current state because it relies on multi user decision making. How to alert the future through dynamic data in the current state, and make the early warning information counterproductive to the user's pre-decision, to achieve the relative balance between the present state and the future expectation, and the stable development of production and management activities, this is a new way of forecasting and warning. This system only considers the regional seasonal agricultural products early-warning forecast, and takes Ji'nan and its surrounding area as the research area. The research object is the ginger product in this area. The research results can also be transplanted to other cities and other crops.

\section{Acknowledgements}

This paper is the stage achievement of National Spark Plan fund project--“Integration and Application of Production and Marketing Price Linkage Early Warning System for Regional and 
Seasonal Agricultural products". This work was financially supported by the National Spark Plan fund project (2014GA740060).

\section{References}

[1] Junwen $\mathrm{Fu}$.Unconventional rising prices of small farmers' products and Study on the long term mechanism of building price stability of agricultural products [J]. Journal of Central University of Finance and Economics, 2011 (2). In Chinese.

[2] CUSHING M J,MARY G.Feedback between wholesale and consumer price inflation:A re-examination of the evidence [J].Southern Economic Journal,1990(56):1059-1072.

[3] TODD E C.Do producer prices lead consumer prices?[J].Economic Review,1995,80(3):25-39.

[4] Shiwei Xu, Zhemin Li, Xiaoxia Dong, et al. Study on price transmission mechanism of Chinese agricultural products between production and marketing [J]. Journal of resource science, 2010,32 (11): 2092-2099. In Chinese.

[5] Guiqin Li. Study on the price formation and stability of vegetable industry chain [D]. Nanjing: Nanjing University of Aeronautics \& Astronautics, 2015:1-148. In Chinese.

[6] Hongye Gao.Western Economics [M]. Beijing:Renmin University of China press, 2011. In Chinese.

[7] Yuhe Song. Study on the relationship between farmers' decision making and price fluctuation of agricultural products ---take fruit vegetables as an example [D]. Beijing: China Agricultural University, 2015:1-113. In Chinese.

[8] Canhuang Chen.The reason,effects and countermeasures for price fluctuation of small farm products in China. [J]. price theory and practice, 2010 (9). In Chinese.

[9] Qiaona Song, Deshan Tang. Agricultural water consumption prediction based on Grey Theory and BP neural network [J]. Agricultural Mechanization Research, 2007,9 (53). In Chinese.

[10] Kongwu Kuang, Xiaomin Wang. Analysis and design of information system [M]. Beijing: Tsinghua University press, 1999. In Chinese.

[11] Wenjun Tian, Changjun Shen, Wengang Zheng, Shirui Zhang, Guanhua Zhou. Design and implementation of price information collection and early warning system for agricultural products. computer engineering and design, 2012,33 (5). In Chinese.

[12] Bing Yu, Tianxiang Yao, Luo Xiang. Prediction of agricultural disaster area in China integrated neural network and grey system. Resources and environment in arid area, 2016.9. In Chinese. 